OPEN ACCESS

Edited by:

Jesse G. Dillon

California State University, Long

Beach, USA

Reviewed by:

Daniel Seth Jones,

University of Minnesota, USA

Rex Malmstrom

Department of Energy Joint Genome

Institute, USA

*Correspondence:

Stephanie A. Carr,

Department of Civil

and Environmental Engineering,

Colorado School of Mines,

1500 Illinois Street,

Golden, CO 80401, USA

scarr@mymail.mines.edu

Specialty section:

This article was submitted to

Extreme Microbiology,

a section of the journal

Frontiers in Microbiology

Received: 30 March 2015

Accepted: 10 August 2015

Published: 26 August 2015

Citation:

Carr SA, Orcutt BN, Mandernack KW and Spear JR (2015) Abundant Atribacteria in deep marine sediment from the Adélie Basin, Antarctica.

Front. Microbiol. 6:872. doi: 10.3389/fmicb.2015.00872

\section{Abundant Atribacteria in deep marine sediment from the Adélie Basin, Antarctica}

\author{
Stephanie A. Carr ${ }^{1 *}$, Beth N. Orcutt ${ }^{2}$, Kevin W. Mandernack ${ }^{3}$ and John R. Spear ${ }^{1}$ \\ ${ }^{1}$ Department of Civil and Environmental Engineering, Colorado School of Mines, Golden, CO, USA, ${ }^{2}$ Bigelow Laboratory for \\ Ocean Sciences, East Boothbay, ME, USA, ${ }^{3}$ Department of Earth Sciences, Indiana University - Purdue University \\ Indianapolis, Indianapolis, IN, USA
}

Bacteria belonging to the newly classified candidate phylum "Atribacteria" (formerly referred to as "OP9" and "JS1") are common in anoxic methane-rich sediments. However, the metabolic functions and biogeochemical role of these microorganisms in the subsurface remains unrealized due to the lack of pure culture representatives. In this study of deep sediment from Antarctica's Adélie Basin, collected during Expedition 318 of the Integrated Ocean Drilling Program (IODP), Atribacteria-related sequences of the $16 \mathrm{~S}$ rRNA gene were abundant (up to $51 \%$ of the sequences) and steadily increased in relative abundance with depth throughout the methane-rich zones. To better understand the metabolic potential of Atribacteria within this environment, and to compare with phylogenetically distinct Atribacteria from non-deep-sea environments, individual cells were sorted for single cell genomics from sediment collected from $97.41 \mathrm{~m}$ below the seafloor from IODP Hole U1357C. As observed for non-marine Atribacteria, a partial single cell genome suggests a heterotrophic metabolism, with Atribacteria potentially producing fermentation products such as acetate, ethanol, and $\mathrm{CO}_{2}$. These products may in turn support methanogens within the sediment microbial community and explain the frequent occurrence of Atribacteria in anoxic methane-rich sediments. This first report of a single cell genome from deep sediment broadens the known diversity within the Atribacteria phylum and highlights the potential role of Atribacteria in carbon cycling in deep sediment.

Keywords: geomicrobiology, methane, sediment, Antarctica, single cell genomics, Atribacteria

\section{Introduction}

Particles fall to the ocean floor from diverse sources at various rates; consequently, available carbon substrates, and redox conditions differ with geographical locations (Jahnke and Jackson, 1992; Jahnke, 1996). Within this spectrum of subseafloor conditions, microbial biomass is estimated to be as great as $3 \times 10^{29}$ cells-similar in magnitude to all life in the ocean water (Kallmeyer et al., 2012) - yet the diversity of metabolic potentials within this environment is largely unexplored due to the particular lack of microbial cultures obtained from subsurface environments. Importantly, global estimates of microbial biomass and metabolic potential in subsurface sediment lack sufficient baseline data, particularly from polar regions where sampling opportunities are very limited. Therefore, it is unclear if diversity trends or microorganisms observed in non-polar regions are also found at higher latitudes. To this end, this study sought to investigate the diversity and metabolic 
functions of microbial communities in deep sediment of the Adélie Basin, a deep bay located $100 \mathrm{~km}$ offshore of Antarctica's Wilkes Land Margin.

The Wilkes Land Margin was targeted by Expedition 318 of the Integrated Ocean Drilling Program (IODP) in 2010 (Expedition 318 Scientists, 2011a). Here, continental and algal detritus fall to the seafloor at a relatively high rate of $\sim 2 \mathrm{~cm} \mathrm{yr}^{-1}$, providing copious organic carbon that is respired by sediment microorganisms, leading to anoxic conditions (Expedition 318 Scientists, 2011). Sulfate concentrations within this basin are quickly depleted within the first $2 \mathrm{~m}$ of the sedimentwater interface. Methane concentrations within this setting reach a maximal concentration of $12.8 \mathrm{mM}$ at $22 \mathrm{~m}$ below seafloor (mbsf; Expedition 318 Scientists, 2011), suggesting active methanogenesis and a narrow sulfate-methane transition zone. This geochemical framework is similar to other nearshore, organic-carbon rich, marine sediment environments (D'Hondt et al., 2002; Inagaki et al., 2006; Webster et al., 2006a) providing an opportunity to compare sediment microbial communities from this Antarctic site to those observed previously.

One common microbial group from near-shore, organic carbon replete, methane-rich marine sediment is the Atribacteria, a recently classified phylum previously referred to as OP9 and JS1 (Rochelle et al., 1992; Hugenholtz et al., 1998; Rinke et al., 2013). Atribacteria have primarily been identified through sequencing of the $16 \mathrm{~S}$ rRNA gene from a number of anoxic sedimentary environments including tidal flats (Wilms et al., 2006; Webster et al., 2007), brackish sediments (Webster et al., 2004; Rinke et al., 2013), mud volcanoes (Niemann et al., 2006), hydrothermal areas (Teske et al., 2002), organic rich deep-sea sediment (Webster et al., 2006a), and the hydratebearing sediments of the Nankai Trough, the Sea of Okhotsk, and the Peru and Cascadia margins (Reed et al., 2002; Inagaki et al., 2003, 2006; Newberry et al., 2004). Of these sites, those associated with methane hydrates have higher relative abundances of Atribacteria sequences, generally over $50 \%$ of sequences (Inagaki et al., 2003, 2006; Newberry et al., 2004), suggesting a selection for Atribacteria in methane-rich sediment (Inagaki et al., 2006). The biogeochemical role(s) of this group within anoxic sediment environments remains unclear given the lack of pure isolates; however, isotope enrichment studies of marine sediment documented the incorporation of ${ }^{13} \mathrm{C}$ labeled acetate and glucose into Atribacteria DNA and suggest a heterotrophic metabolism (Webster et al., 2006b).

Atribacteria have also been identified in non-marine settings such as terrestrial hot springs and anaerobic sludge bioreactors (Chouari et al., 2005; Dodsworth et al., 2013). Single cell genomic (Dodsworth et al., 2013; Rinke et al., 2013) and metagenomic (Dodsworth et al., 2013) approaches have been applied to some of these non-marine samples to determine the genetic potential of this group. For example, two candidate Atribacteria species-Candidatus Caldatribacterium californiense and $\mathrm{Ca}$. Caldatribateriam saccharofermentans-were identified from geothermal hot springs (Dodsworth et al., 2013). Both are hypothesized to produce hydrogen, acetate, and ethanol as a result of sugar fermentation, further supporting the inference of a heterotrophic lifestyle from marine enrichments (Webster et al., 2006b).

Considering that Atribacteria are known to be abundant in organic rich marine sediment, that fermentative lifestyles are suggested from genomic studies of non-marine Atribacteria, and that fermentation is a likely process in the anoxic sediment of the Adélie Basin, this study provided a natural laboratory for exploring the possible role of Atribacteria in marine sediment biogeochemistry. We first examined the sequence abundance of this group in Adélie Basin sediments in the context of sediment biogeochemical processes. We then applied single cell genomic approaches (Stepanauskas and Sieracki, 2007; Rinke et al., 2013; Lasken and McLean, 2014) to explore the genetic potential of this group, leveraging off recently developed techniques used to examine uncultivated microorganisms from shallow (<8 mbsf) sediment (Lloyd et al., 2013; Kaster et al., 2014; Wasmund et al., 2014). Focusing on a deep sediment sample (97.41 mbsf) with a high relative abundance of Atribacteria (based on 16S rRNA gene pyrotag sequencing), we provide the first microbial data from the deep biosphere of a remote and highly productive region off Antarctica, the first partial genome from deep subsurface sediment, and the first partial genome of a marine Atribacteria cell. The work presented here investigates the metabolic potential of Atribacteria, and the potential involvement of this group in carbon cycling in marine sediment.

\section{Materials and Methods}

\section{Sample Collection}

Sediment of the Adélie Basin was sampled during IODP Expedition 318 in 2010 from borehole U1357C, which is described in further detail elsewhere (Expedition 318 Scientists, 2011a). Briefly, Site U1357 is located directly offshore of the Adélie Drift along the Wilkes Land Margin $\left(66^{\circ} 24.8^{\prime} \mathrm{S}\right.$, $140^{\circ} 25.5^{\prime} \mathrm{E}$, Figure 1) at roughly $1000 \mathrm{~m}$ water depth. The recovered sediment consisted primarily of diatom ooze (80-99\%) with occasional fine layers of clay and silt in alternating greenish brown and olive green varves representing annual algal blooms. High annual primary productivity in surface ocean waters coupled with terrestrial runoff from the Antarctic mainland leads to relatively high sedimentation rates of $2 \mathrm{~cm} \mathrm{yr}^{-1}$ (Expedition 318 Scientists, 2011).

Samples for molecular biological analysis were collected shipboard as described in detail elsewhere (Expedition 318 Scientists, 2011b). Briefly, $10 \mathrm{~cm}$ sections of the intact core were taken for interstitial water geochemistry and molecular analysis at varying depth resolution throughout the core. For molecular analyses, sterile cut-end $5 \mathrm{~mL}$ syringes were used to collect sediment from the center of core sections; these were immediately frozen at $-80^{\circ} \mathrm{C}$ and maintained at this temperature during transport and storage to the home laboratory. While contamination tracers such as microspheres or perfluorocarbons (Lever et al., 2006) were not used during this expedition, samples collected from the ends of each core had anomalously high sulfate concentrations (a rough measure of contamination from 


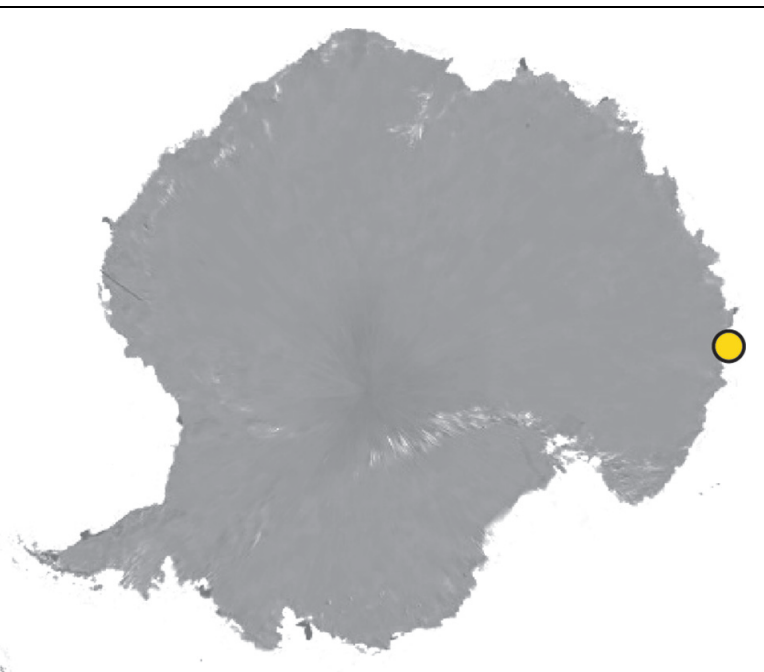

FIGURE 1 | Location of IODP Site U1357 in the Adélie Basin offshore Antarctica (Antarctic Image Source: "Antarctica" $90^{\circ} \mathrm{S}$, and $0^{\circ} \mathrm{E}$. Google Earth, December 13, 1998, accessed December 1, 2014).

seawater intrusion into sediment). DNA extracts from these samples (20 of 60 samples collected) were not analyzed.

Sediment geochemical data such as total organic carbon, dissolved inorganic carbon, methane, and sulfate concentrations were reported previously (Expedition 318 Scientists, 2011). To summarized briefly, concentrations of total organic carbon within the top $100 \mathrm{~m}$ of the core average $1.6 \pm 0.2 \%$ weight percent, which is similar in concentration to other near-shore sediment of similar depth (Jahnke, 1996). Dissolved inorganic carbon was relatively high, increasing from 40 to $80 \mathrm{mM}$ within the upper $20 \mathrm{~m}$ of sediment (deeper values are not available), indicating high organic carbon remineralization. Methane concentrations peaked at $12.8 \mathrm{mM}$ at $21.61 \mathrm{mbsf}$, with a secondary peak of $5.2 \mathrm{mM}$ at $68.79 \mathrm{mbsf}$ (Figure 2). Sulfate was quickly depleted to below detection limit $(10 \mu \mathrm{M}$, data not shown) within the first two meters of the sediment-water interface.

\section{DNA Extractions}

Genomic DNA was extracted from sediment samples using a bead beating/phenol chloroform protocol modified from Zhou et al. (1996). Briefly, 0.1-1.0 g of sediment was diluted with $2 \mathrm{~mL}$ of lysis buffer (100 mM Tris [pH 8.0], $100 \mathrm{mM}$ ethylenediaminetetraacetic acid (EDTA), $100 \mathrm{mM} \mathrm{NaH} \mathrm{PO}_{4}$, $1.5 \mathrm{M} \mathrm{NaCl}, 1 \%$ [w/v] cetrimonium bromide) and homogenized on a mini beadbeater (Biospec Products, Bartlesville, OK, USA) with $0.1 \mathrm{~mm}$ zircon beads for $30 \mathrm{~s}$ at the homogenize setting. Fifty microliter of a proteinase K solution $(20 \mathrm{mg} / \mathrm{ml})$ was added and samples were shaken at $150 \mathrm{rpm}$ at $37^{\circ} \mathrm{C}$ for $30 \mathrm{~min}$. Subsequently, $10 \mathrm{~mL}$ of $20 \%$ [w/v] sodium dodecyl sulfate (SDS) solution was added, and samples were incubated at $65^{\circ} \mathrm{C}$ for $2 \mathrm{~h}$ with inversions every $15 \mathrm{~min}$. Samples were centrifuged at $6,000 \times g$ for $10 \mathrm{~min}$, and supernatants were decanted into clean microcentrifuge tubes. The remaining sediment was extracted a second time by adding an additional $1 \mathrm{~mL}$ of the lysis buffer and $10 \mathrm{~mL}$ of SDS, vortexing, incubating at $65^{\circ} \mathrm{C}$ for $10 \mathrm{~min}$, centrifuging as above, and then combining the supernatants. Nucleic acids were extracted from the supernatants with an equal volume of phenol:chloroform:isoamyl alcohol $(25: 24: 1[\mathrm{v} / \mathrm{v} / \mathrm{v}]$; pH 8.0,10 mM Tris, $1 \mathrm{mM}$ EDTA) followed by a second extraction with an equal volume of chloroform:isoamyl alcohol (24:1 [v/v]). Nucleic acids were precipitated with an equal volume of iced isopropanol and 10\% [v/v] $3 \mathrm{M}$ sodium acetate, followed by two ice cold $70 \%$ ethanol washes. Precipitates were brown in color with suspected humics and were purified using an ethidium bromide high salt extraction (Stemmer, 1991). Nucleic acids were resuspended in nuclease free water. Samples and extraction blanks were screened for amplifiable DNA by polymerase chain reaction (PCR) with PCR Master Mix (Promega \#M7502) and the modified universal primers $515 \mathrm{f}$ and $927 \mathrm{r}$ of Osburn et al. (2011) using the following reaction conditions: $94^{\circ} \mathrm{C}$ denaturation for $2 \mathrm{~min} ; 30$ cycles of $95^{\circ} \mathrm{C}$ for $30 \mathrm{~s}, 55^{\circ} \mathrm{C}$ for $30 \mathrm{~s}$, and $72^{\circ} \mathrm{C}$ for $45 \mathrm{~s}$; and a final elongation step at $72^{\circ} \mathrm{C}$ for $5 \mathrm{~min}$ PCR product was then loaded onto an agarose gel to check for product bands with ethidium bromide staining. All extraction blanks yielded negative results.

\section{Pyrosequencing and Bioinformatic Processing}

Amplicons of the 16S rRNA gene were prepared for 454 pyrosequencing using a PCR-touchdown annealing temperature strategy from Don et al. (1991) with procedure modifications and modified universal primers $515 \mathrm{f}$ and $927 \mathrm{r}$ of Osburn et al. (2011). These modified primers were selected based on improved coverage of the V4 and V5 region of the 16S rRNA gene (Osburn et al., 2011). According to the Silva TestProbe 3.0, forward and reverse primers covered 79.8 and $75.4 \%$ of archaea and 79.1 and $76.1 \%$ of bacteria with no mismatches, respectively (Pruesse et al., 2007). Forward primers included the 454 Life Science A adaptors and a sample specific $8 \mathrm{nt}$ barcode. The reverse primer included the 454 Life Science B adaptors. Amplicon concentrations for each sample were quantified using a 2100 Bioanalyzer (Agilent Technologies, Colorado Springs, CO, USA), pooled (22 ng DNA/sample) and concentrated using a Savant DNA 12 Speed Vac Concentrator (Thermo Scientific, Waltham, MA, USA). The pooled DNA was gel purified using the Montage DNA Gel Extraction Kit (Millipore, Bellerica, MA, USA), and sequenced on a Roche 454 FLX titanium platform at Engencore, University of South Carolina (now Selah Genomics).

Pyrosequencing reads were analyzed using the Quantitative Insights Into Microbial Ecology (QIIME) Pipeline (Caporaso et al., 2010). Reads between 200 and 500 base pairs with a quality score of 27 or above were denoised using the QIIME denoiser for titanium runs, and clustered into operational taxonomic units (OTUs) at a 97\% similarity threshold using UCLUST (Edgar, 2010). Taxonomy of OTUs was assigned by BLAST (Altschul et al., 1990) against the Silva SSU NR Reference database, release 102 (Pruesse et al., 2007) within QIIME. Chimeras were identified and removed using QIIME's ChimeraSlayer Wrapper. Extraction replicates demonstrated consistent community results (Supplementary Figure S1), with Pearson Correlation coefficients 


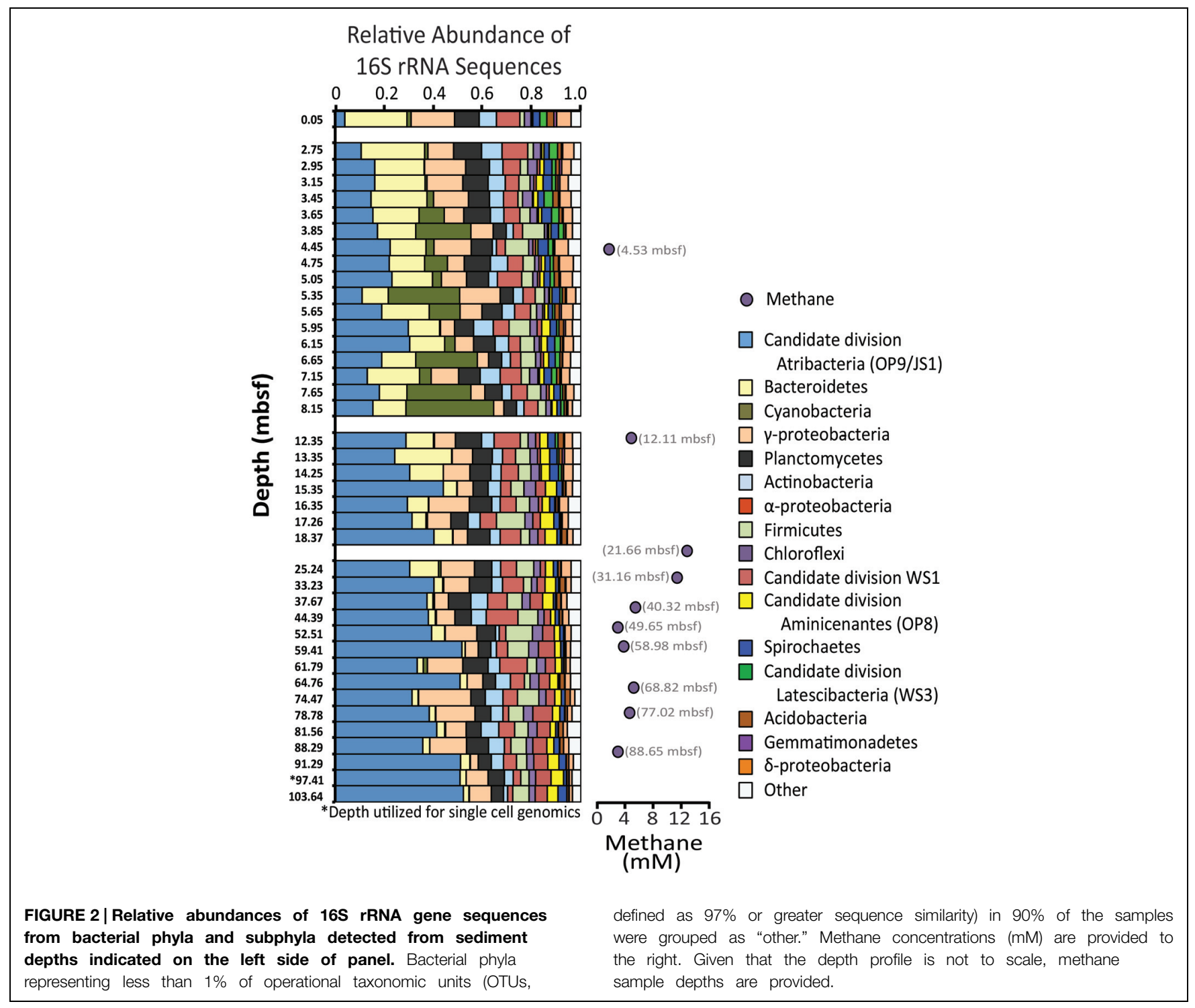

$>0.96$. Sequences were deposited in the MG-RAST database under accession numbers 4624791.3-4634830.3.

\section{Single Cell Sorting, Genome Amplification, Sequencing, and Annotation}

Sorting of individual cells from unfixed frozen sediment from $97.41 \mathrm{mbsf}$ was attempted for single cell genomics using the Single Cell Genomics Center (SCGC) at the Bigelow Laboratory for Ocean Sciences. While the sediment was not preserved with recommended fixatives to prevent cell lysis during storage (Swan et al., 2011; Stepanauskas, 2012; Lloyd et al., 2013), and although the samples had gone through at least one round of freeze-thaw for bulk DNA extraction which may have introduced cell lysis, the high relative abundance of target microorganisms in the sample suggested this approach might still be successful in recovering intact cells. Approximately $0.5 \mathrm{~g}$ of frozen sediment was diluted in $1 \mathrm{~mL}$ of filter-sterilized seawater and vortexed for $30 \mathrm{~s}$ to liberate cells from the sediment matrix, modifying methods developed previously (Lloyd et al., 2013). Sediment was then separated from cells by gentle centrifugation at $2000 \mathrm{rpm}$ for $30 \mathrm{~s}$ The cell suspension was treated with SYTO-9 DNA stain and sorted into two 384-well plates using SCGC's standard pipeline. Both sorted plates were subjected to physical lysis treatments (five freezethaw cycles), and the second plate also experienced an alkaline lysis treatment (Raghunathan et al., 2005). DNA amplification by multiple displacement amplification was performed according to published protocols (Swan et al., 2011). A total of eight amplification reactions had successful DNA amplification from the two plates, but only one of these reactions had a positive screen for Atribacteria with bacterial specific 16S rRNA gene primers (27F and 907R; Lane, 1991). This low recovery rate is likely a result of not fixing the samples to prevent cell lysis and/or different susceptibility of deep sediment cells to cell lysis.

The initial assembly of Atribacteria bacterium SCGC AD561-N23 is publically available within the IMG system (taxon 
ID 2588254308) and the sequence for the $16 \mathrm{~S}$ rRNA gene is available within the IMG system and Supplementary Materials. A detailed assembly procedure can be downloaded from the QC.finalReport.pdf available at http://genome.jgi.doe.gov/ CandivSCAD561N23/CandivSCAD561N23.download.html.

Briefly, single-cell amplified genomic (SAG) DNA was sequenced, assembled and annotated at the United States Department of Energy's Joint Genome Institute (JGI) following their standard pipeline for Illumina HiSeq 2000 platform sequencing. Illumina reads were screened using JGI's in-house DUK filtering program (Mingkun et al., unpublished). Trimmed reads were assembled using SPAdes (version 3.0.0) with the following parameters $(-\mathrm{t}$ 8 -m 40 - -sc - -careful - -12; Bankevich et al., 2012). Once released to Integrated Microbial Genomes (IMG) system, manual screening and removal of potential contaminate sequences according to JGI's single cell data decontamination protocol (Clingenpeel, 2015). Scaffolds with GC contents that varied from the genome average more than $10 \%$ and clustered as a distinct group according to a kmer analysis (IMG, fragment window $5000 \mathrm{bp}$, fragment step $500 \mathrm{bp}$, oligomer size 5, minimum variation 10) were identified as potential contaminates and were removed from the de novo assembly (with the exception of scaffolds that contained ribosomal DNA). This screened genome was submitted to the IMG database as GOLD project Gp0087948, titled "Candidate division JS1 bacterium SCGC AD-560-N23 (manually screened)."

Gene annotations were performed using both IMG and the Rapid Annotation using Subsystem Technology (RAST) platforms (Aziz et al., 2008; Overbeek et al., 2013; Markowitz et al., 2014). Discrepancies between annotations were investigated by comparing coding sequences of genes against GenBank non-redundant protein sequence and SwissProt Databases by BLASTP (Altschul et al., 1990). Genome completeness was estimated by comparing the annotated genome sequence against a list of conserved single copy bacterial genes (Rinke et al., 2013) using HMMER3 software (Eddy, 2011). Average nucleotide identify (ANI) comparisons between the one single cell genome from this study and publically available genomes from Atribacteria (Table 1) were calculated using JSpecies software (Richter and Rosselló-Móra, 2009) and standard parameters determined elsewhere (Goris et al., 2007).

\section{Phylogenetic Tree Construction}

Operational taxonomic units identified from pyrosequencing and the 16S rRNA gene sequences for the one single cell genome were phylogenetically compared to an Atribacteria (i.e., OP9 and JS1) reference tree. The reference tree was reconstructed using the same 204 Atribacteria sequences and 11 Gemmatimonadetes sequences utilized by Yarza et al. (2014) and five publicly available Atribacteria genomes (Table 1). Sequence alignments were constructed using SSU-align and regions of low posterior probabilities were masked out using SSU-mask (Nawrocki et al., 2009). A phylogenetic tree was constructed using RaxML version 7.2.7 with the rapid bootstrapping algorithm and GTRGAMMA as the nucleotide substitution model and evolutionary mode (Stamatakis et al., 2008). Bootstrap values were calculated from 1000 bootstrap inferences. The 16S rRNA gene sequences from Atribacteria bacterium SCGC AD-561-N28, OTUs 613, and 2153 and a closely related short $(<1200 \mathrm{bp})$ Atribacteria sequences from Antarctic settings (AF147496) were aligned using the same filter mask developed for the reference tree alignment (Altschul et al., 1990; Desantis et al., 2006). Aligned sequences were then placed into the constructed phylogenic tree using pplacer (Matsen et al., 2010).

\section{Results and Discussion}

\section{Microbial Community Composition of Deep Adélie Basin Sediment}

Pyrosequencing of the 16S rRNA gene was performed at 40 sample depths (0.05-104 mbsf) to evaluate changes of the microbial diversity with depth in Antarctic sediment. After quality control filtering, a total of 107,092 sequences were deemed suitable for taxonomic assignment, averaging 2,677 sequence reads per sample. Sequence reads were clustered as 2,221 OTUs and 43 different bacterial phyla (Figure 2, Supplementary Table S1). Phyla that represented more than $10 \%$

TABLE 1 | Genome characteristics of single amplified genomes (SAGs) from Atribacteria, including sample location and GC content.

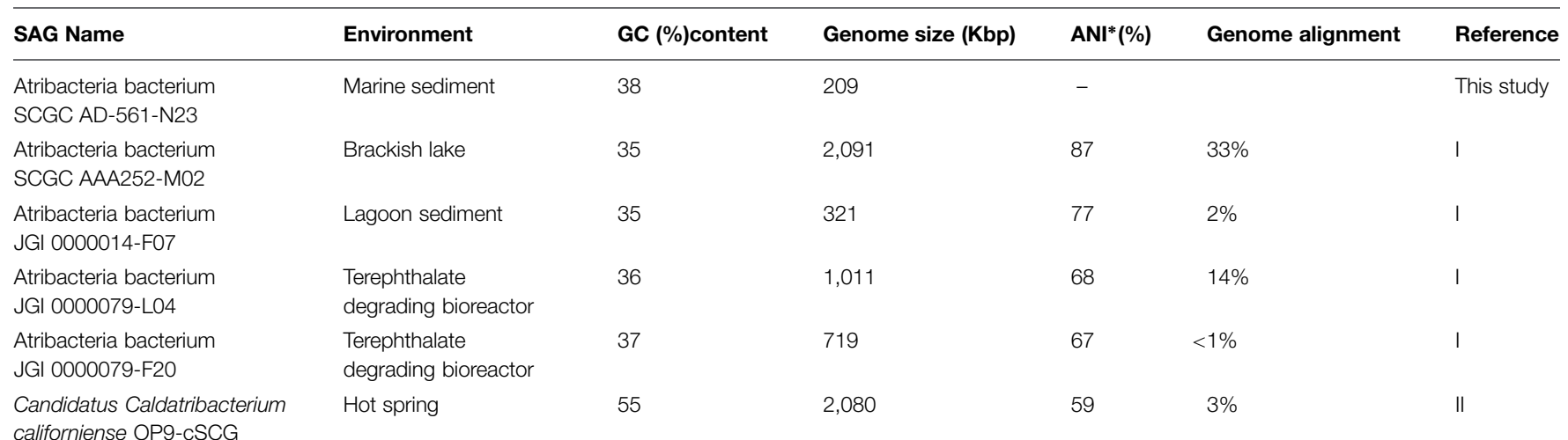

*Average nucleotide identity comparison between Antarctic bacterium SCGC AD-561-N23 and the given SAG and the percentage of I. Rinke et al., 2013; II. Dodsworth et al., 2013. 
of the sequenced community at any one sampling depth included Actinobacteria, Atribacteria, Bacteroidetes, Planctomycetes, and the sub-phyla Alpha- and Gammaproteobacteria. Cyanobacteria sequences consisted of chloroplast $16 \mathrm{~S}$ rRNA genes, suspected to be fossilized DNA or cells, derived from surface waters and well preserved in this anoxic environment. Other phyla that represented more than $1 \%$ of the sequenced community included Acidobacteria, Chloroflexi, Firmicutes, Spirochaetes, sub-phylum Deltaproteobacteria, Aminicenantes (formerly Candidate Division OP8), Latescibacteria (formerly Candidate Division WS3), and Candidate DivisionWS1. Similar to Antarctic sediments of the Ross Sea (Carr et al., 2013), it appears that the bacterial communities were dominated by heterotrophic organisms, based on the energy metabolisms of closely related cultured organisms. For example the majority of Bacteroidetes OTUs were classified as Sphingobacteria, anaerobic heterotrophs often associated with hydrolytic and fermenting abilities (Cottrell and Kirchman, 2000). Additionally, most of the sequenced Actinobacteria OTUs were classified as Acidimicrobineae, a group capable of breaking down complex organic material (McCarthy and Williams, 1992; Schrempf, 2001; Vorob'ev et al., 2007).

Notably, sequences related to Atribacteria increased in relative abundance with depth in the sediment, ranging from less than $5 \%$ in shallow samples $(0.05 \mathrm{mbsf})$ and became the dominant group in deeper samples, representing over $50 \%$ at $103.6 \mathrm{mbsf}$ (Figure 2). The vast majority (94\%) of the Atribacteria sequences grouped within two OTUs, referred to as OTU 613 and OTU 2153. OTU 2153 dominated in sediment depths above the maximum methane concentration $(12.8 \mathrm{mM})$, while OTU 613 dominated in the deeper sediment depths (Figure 3). Phylogenetic analysis of these two OTUs revealed that they cluster most closely to sequences from other anoxic marine sediment samples as opposed to sequences from bioreactors or terrestrial hot springs (Figure 4). Moreover, OTU 613 grouped closely (99-100\% sequence similarity, Supplementary Table S2) to sequences from other Antarctica lake sediment (Bowman et al., 2000), suggesting that geographic location as well as environmental conditions contribute to phylogenetic diversity. Overall, the microbial composition and relative sequence abundances of Atribacteria measured at this site were similar to those observed within methane-rich hydrate-bearing sediments (Inagaki et al., 2003, 2006; Newberry et al., 2004). The lack of a bottom simulating reflector in this basin (Escutia et al., 2008) and constant salinity values suggest the absence of hydrates in the Adélie Basin; however, methane concentrations at this site are still rather high (Figure 2), supporting an association of Atribacteria with high-methane conditions.

\section{Genome Characteristics of a Single Atribacteria Cell from Deep Adélie Basin Sediment}

Sediments for the Adélie Basin were frozen upon collection, and thus considered to be non-ideal for single cell techniques. However, given our desire to focus on the functionality of Atribacteria and the relatively large proportion of Atribacteria sequence reads, we attempted the challenge of cell sorting. Flow cytometric scattergrams of diluted sediment slurries indicated probable success for sorting intact cells (Supplementary Figure S2). A total of 768 potential cells were sorted. MDA reactions resulted in only eight successful amplifications, of which only one was identified as Atribacteria. Considering that these samples had already experienced several freeze thaw cycles, we hypothesize that cell resistance to lysis techniques is likely responsible for these limited results. However, the successful isolation of an Atribacteria cell does indicate the potential use of single cell techniques with frozen sediments, especially if more appropriate cell lysis procedures can be adapted. Given

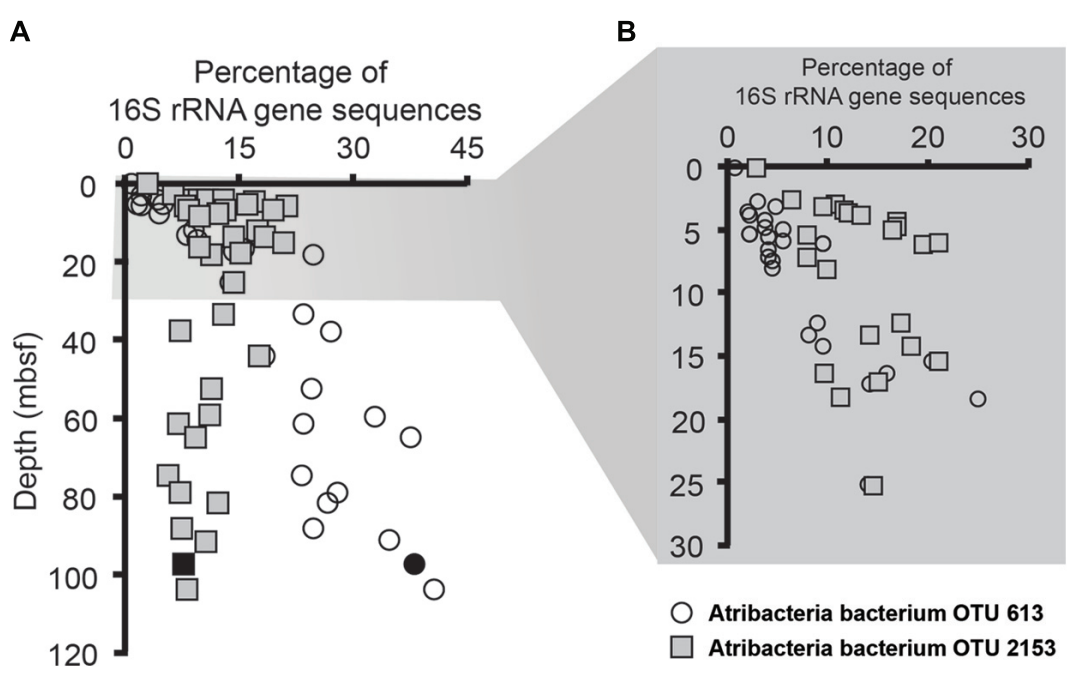

FIGURE 3 | Relative abundances of Atribacteria OTUs 2153 (squares) and 613 (circles) sequences determined by pyrosequencing. (A) This includes samples throughout the entire core, while (B) focuses on the top $30 \mathrm{~m}$ below seafloor (mbsf). Solid black symbols represent the sample utilized for single cell genomics. 

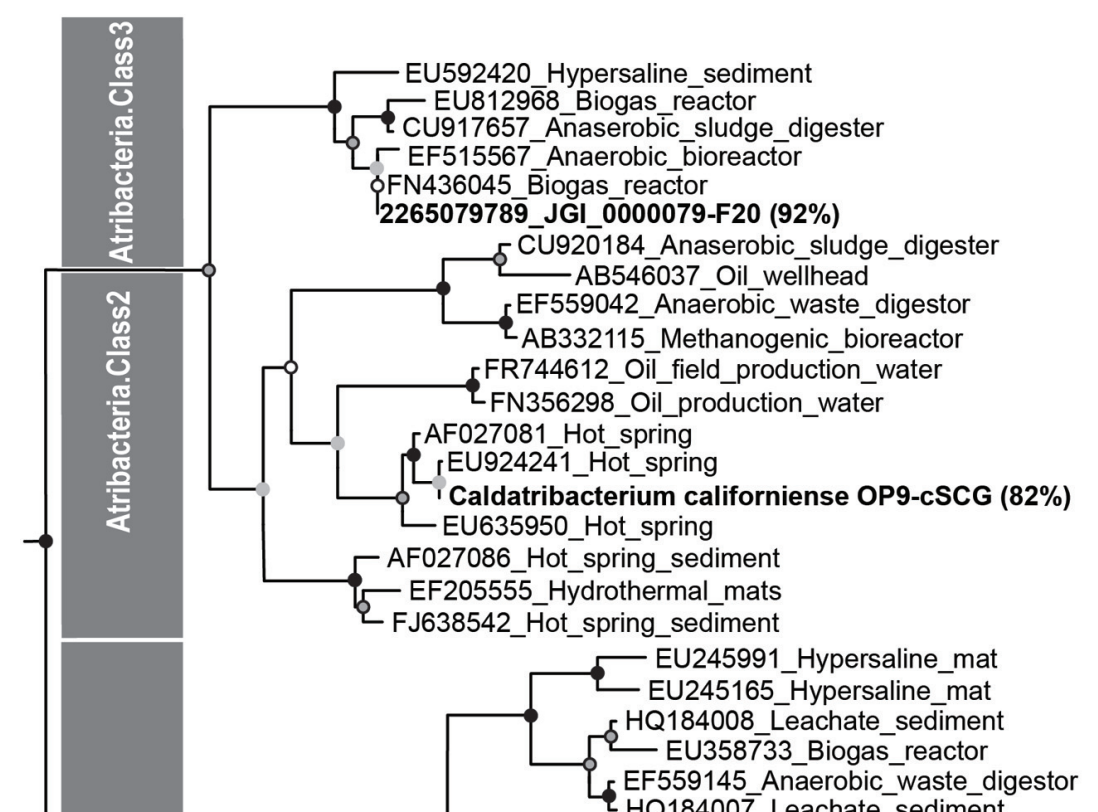

L EF559145_Anaerobic_waste_dig

2265079445_JGI_0000079-L04 (92\%)

_GQ415367_Öil_field_production_water
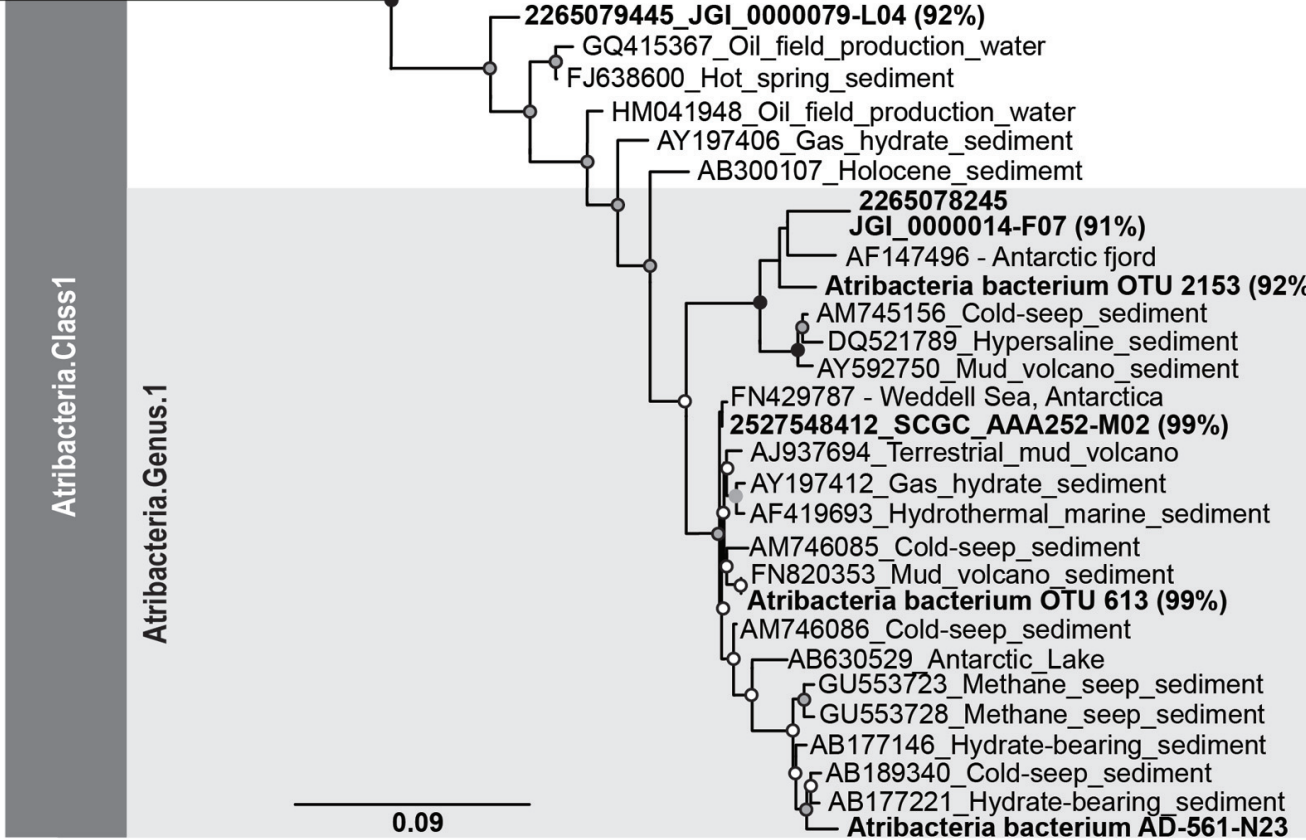

FIGURE 4 | Phylogenetic associations of Atribacteria based on the 16S rRNA gene. Bold sequences indicate sequences from this study, while sequences from other studies are indicated with Genbank accession ID numbers. Percentages represent the 16S rRNA gene similarity to the subsurface Antarctic bacterium SCGC AD-561-N23 single amplified genome according to BLAST analyses.

the amount of existing frozen sediment samples that have been collected for biological studies throughout the history of oceanic drilling programs, improved techniques could unlock a huge amount of currently stored genomic information.

The one successful single cell amplified genome (Atribacteria bacterium SCGC AD-561-N23) contained a 16S rRNA gene sequence that shared $99 \%$ sequence similarity to the Atribacteria OTU 613 (Figure 4), which was the dominant OTU in the deeper samples (Figure 3). To our knowledge, this
Atribacteria cell is the first reported cell to be isolated from a deep (>10 mbsf) subsurface sediment. While the single cell DNA amplification success rate was lower than those from other sedimentary environments (Lloyd et al., 2013; Kaster et al., 2014; Wasmund et al., 2014), genome amplification of any cell is remarkable considering that the samples were not preserved for single cell sorting and amplification upon collection. The final genome assembly size was $209 \mathrm{kbp}$ with 24 scaffolds (Table 2). A total of 207 coding sequences were 
TABLE 2 | Genomic characteristics of Atribacteria bacterium SCGC AD-561-N23 from deep Antarctica sediment.

\begin{tabular}{ll}
\hline Characteristic & Value \\
\hline Assembly size & 209,267 bp \\
Contigs & 24 \\
Longest contig & 27,948 bp \\
N50 & 14516 \\
Coding sequences & 207 \\
Non-hypothetical proteins & 137 \\
Ribosomal proteins & 12 \\
GC content & $38 \%$ \\
Level of completeness & $15 \%$ \\
\hline
\end{tabular}

annotated. Coding sequences identified as putative proteins were most abundant (70 coding sequences), followed by those related to replication, transcription, and translation functions (Supplementary Table S3). Based on the identification of 21 out of 139 conserved bacterial genes (Rinke et al., 2013), genome completeness was estimated to be $15 \%$. Amplification bias during MDA reactions is the suspected cause of the low genomic coverage and is not uncommon for environmental samples (Raghunathan et al., 2005; Lasken, 2007).

Phylogenic reconstruction of the candidate phylum Atribacteria based on the 16S rRNA gene identifies three different classes (Yarza et al., 2014). According to these taxonomic classifications, Atribacteria bacterium SCGC AD561-N23, OTU 613, and OTU 2153 are all affiliated with candidate taxonomic unit (CTU) Atribacteria.Class1, and more specifically Atribacteria.Genus1 (Figure 4). A comparison between the SAG of this study and SAGs sampled from terrestrial and aquatic environments revealed a range of sequence similarity (82-98\%), with higher similarity to SAGs from cool, saline environments than to SAGs from anaerobic bioreactors and terrestrial hot springs (Figure 4). Atribacteria bacterium SCGC AAA252-M02 and Atribacteria bacterium JGI 0000014-F07 share the highest percentage of similarity with the SAG from this study (98 and 91\%, respectively), with the former grouping in the same candidate genus (Figure 4). Atribacteria bacterium JGI 0000079-L04 is also identified as Atribacteria.Class1 but falls outside of the Atribacteria.Genus1 classification. Atribacteria bacterium JGI 0000079-F20 and Ca. C. californiense are affiliated with Atribacteria.Class3 and Atribacteria.Class2, respectively.

Similar grouping trends are observed when comparing GC content and ANI of the SAGs. The GC content for the partial genome of Atribacteria bacterium SCGC AD-561-N23 was 38\%, which is similar to most other Atribacteria SAGs (35-37\%, Table 1), although C. californiense with a hot-spring origin has a GC content of 55\% (Dodsworth et al., 2013). The calculated ANI values of shared oligonucleotide sequences illustrate that the Atribacteria bacterium SCGC AD-561-N23 SAG is 87 and $77 \%$ similar to SAGs collected from brackish water and lagoon sediments, respectively, while it is only $59 \%$ similar to the C. californiense from a hot spring (Table 1). Genome coverage for ANI comparisons against C. Californiense, Atribacteria bacterium JGI 0000079-F20 and Atribacteria bacterium JGI 0000014-F07 were very low ( $<4 \%$ genome coverage) and should be interpreted which caution (Richter and Rosselló-Móra, 2009). Nevertheless, collectively, these similarity trends suggest that the SAG of this study is most comparable to organisms collected from marine-like settings; therefore these SAGs are expected to share physiological traits.

\section{Heterotrophic Metabolic Potential of Sediment Atribacteria}

Similar to previously investigated Atribacteria SAGs, the subsurface Atribacteria bacterium SCGC AD-561-N23 appears to be heterotrophic, based on genomic observation of sugar and amino-sugar metabolic and fermentation pathways (Figure 5). Sugar metabolism by Atribacteria bacterium SCGC AD-561$\mathrm{N} 23$ is evident by several sugar membrane transporters and permeases, including those specifically for ribose sugar (Figure 5, Supplementary Table S4, IMG ID 2590808876). Coding sequences for hexose kinase (IMG ID 2590809017, EC:2.7.1.2), fructose 1-6 bisphosphate aldolase (IMG ID 2590809081 EC:4.1.2.13), and pyruvate kinase genes (IMG ID 2590808886, EC:2.7.1.40) indicate Embden-Meyerhof glycolysis and the anaerobic catabolism of six carbon sugars.

When considering the potential for fermentation by sediment Atribacteria (Figure 5, Supplementary Table S3), the reduction of pyruvate to $\mathrm{CO}_{2}$ and acetyl-CoA is evident by coding sequences for pyruvate:ferredoxin oxidoreductase (IMG IDs 2590808972 and 2590808975) and the required co-factor thiamine pyrophosphate (IMG ID 2590808973; Uyeda and Rabinowitz, 1971). The presence of acetate kinase (2590808976, EC: 2.7.2.1) and alcohol dehydrogenase (2590809027, EC:1.1.1.1) suggests additional fermentation of pyruvate to acetate or ethanol may be possible. The same genes were identified within C. californiense, and the more closely related Atribacteria SAGs SCGC AAA252-M02, further supporting the possibility of fermentation pathways in Atribacteria bacterium SCGC AD-561-N23.

Amino-sugar metabolism is also evident in Atribacteria bacterium SCGC AD-561-N23 (Figure 5). Amino sugars such as $\mathrm{N}$-acetyl-D-glucosamine-6-phopate could be transported into the cell by ATP-driven ABC transporters encoded within this SAG (IMG ID 2590809113). Once in the cell, the amino sugars could be converted to fructose-6-phosphate by $N$-aceylglucosamine-6-phosphate amidohydrolase (IMG IDs 2590808895 and 2590809033, EC:3.5.1.22) and glucosamine-6phosphate deaminase (2590809032, EC:3.5.99.6). The resulting fructose-6-phosphate may be further degraded via glycolysis as noted above. Additional acetate and $\mathrm{NH}_{3}$ products could be potentially used in many processes, including amino acid metabolism, lipid synthesis, or ethanol fermentation.

\section{Metabolic and Functional Diversity within the Atribacteria Phylum}

There is no evidence that Atribacteria are directly involved in methane production or consumption, although this might be speculated based on the co-occurrence of Atribacteria in methane rich sediment (Figure 3). Instead, the partial genome of Atribacteria bacterium SCGC AD-561-N23 suggests that Atribacteria produce fermentation products such as acetate, 


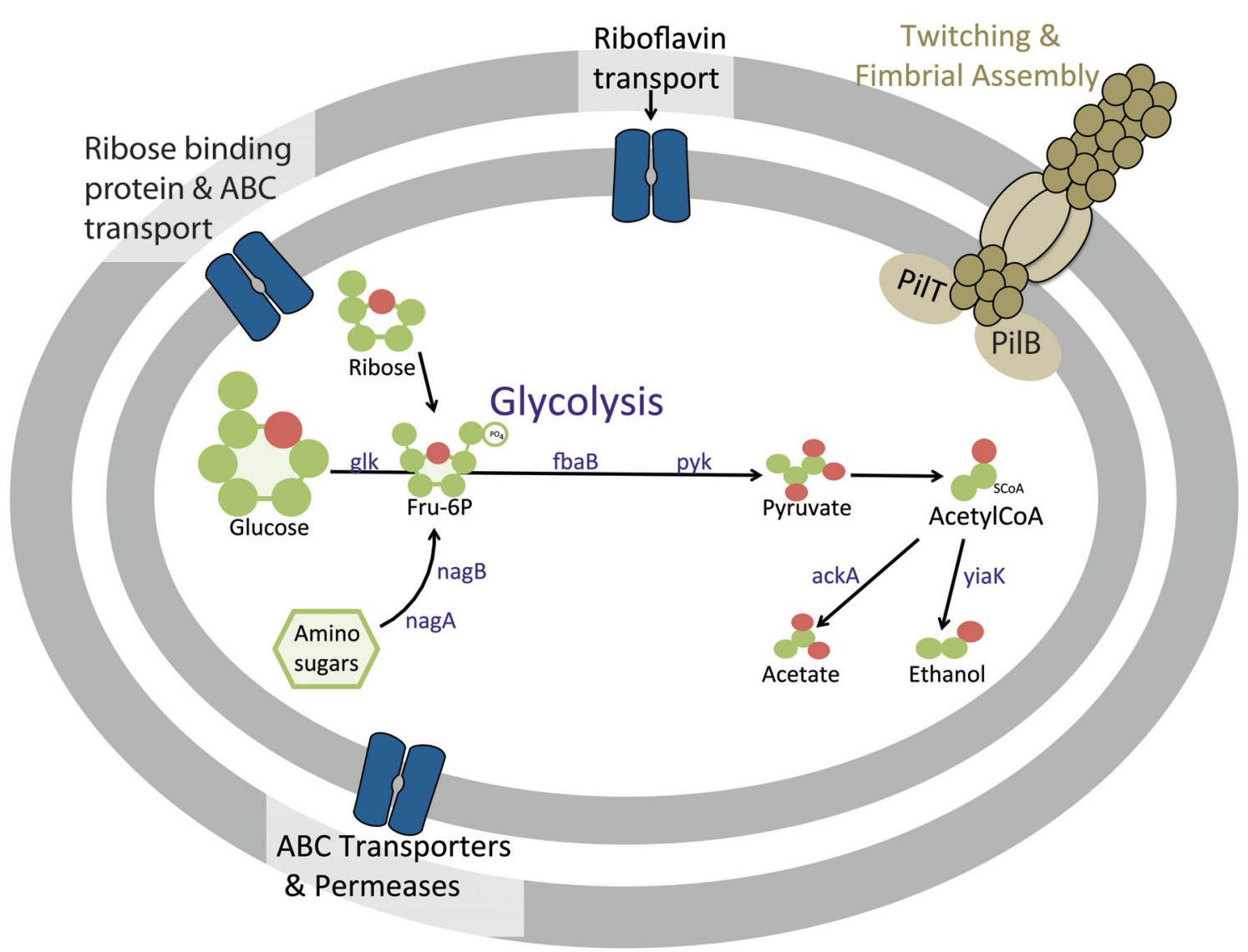

FIGURE 5 |Cartoon schematic of proteins in Atribacteria bacterium SCGC AD-561-N23 associated with heterotrophic metabolism and motility functions. Abbreviations: ABC, ATP-binding cassette; ackA, acetate kinase; glk, glucose/hexose kinase; fbaB, fructose 1-6 bisphosphate aldolase; nagA, $N$-aceylglucosamine-6-phosphate amidohydrolase; nagB, glucosamine-6-phosphate deaminase; pyk, pyruvate kinase; yaik, alcohol dehydrogenase. ethanol and $\mathrm{CO}_{2}$ that could be used as substrates by methanogenic organisms. Few archaea, including methanogens, were observed in the pyrosequencing survey (less than $<0.2 \%$ total sequences; Carr, 2012). This absence may be the result of primer bias (Teske and Sørensen, 2007), however, we hypothesize that methane-producing organisms are in relatively low relative abundance, as has been observed in other methanerich sediment environments (Inagaki et al., 2006; Colwell et al., 2008). Active methanogenesis is evident from increasing methane concentrations and an enrichment of dissolved inorganic carbon ${ }^{13} \mathrm{C}$ values with sediment depth (Carr, 2012). A similar relationship between heterotrophic Atribacteria and methanogens has been proposed within the water column of a meromictic, brackish lake (Gies et al., 2014). From that environment, the genome of Atribacteria bacterium SCGC AAA252-M02 indicates acetate oxidation and the production of $\mathrm{CO}_{2}$ and $\mathrm{H}_{2}$ using the Wood-Ljungdahl pathway in reverse (Müller et al., 2013). Atribacteria bacterium JGI 0000079-L04, which is classified within the same class as Atribacteria bacteria SCGC AAA252-M02 and SCGC AD-5601-N23, also contains many coding sequences for the Wood-Ljungdahl pathway
(Nobu et al., 2015). Atribacteria bacterium SCGC AD-5601N23 lacks evidence of this pathway, but given the low genome coverage, and the close relation to SCGC AAA252-M02 and JGI 0000079-L04, it is possible that bacterium SCGC AD5601-N23 also contains these genes. However, regardless if Atribacteria bacterium SCGC AD-5601-N23 is capable of both acetate oxidation and sugar fermentation, or sugar fermentation alone, the interpretation here presents preliminary evidence for a heterotrophic lifestyle and the production of simple carbon substrates that could fuel methanogenesis. Given the importance of fermenters to methanogenic communities (Kirchman et al., 2014), our initiatory results provide compelling motivation for future investigations of sedimentary Atribacteria. We expect that these additional studies will provide valuable insight to the heterotrophic capabilities of Atribacteria, their potential indirect interactions with methanogens and ultimately, the biogeochemistry of carbon cycling and methane production in marine sediment.

In summary, pyrosequencing of the $16 \mathrm{~S}$ rRNA gene revealed a large relative abundance of sequence reads classified as Atribacteria within sediments of the Adélie Basin. While samples 
were not originally collected and preserved for single cell analyses, we demonstrated the first successful isolation of a deep $(>10)$ subsurface cell. This success highlights the potential application of single cell techniques to stored frozen sediment samples, but also recognizes the potential need for more aggressive cellular lysis procedures. The preliminary genomic data presented here, along with sediment biogeochemistry and molecular biology suggests that the abundant Atribacteria in deep methane-rich marine sediment are heterotrophic, providing fermentative precursors for methane production by other organisms. Although there is no known cultured representative from the Atribacteria phylum, culture-independent single cell genomes derived from terrestrial and aquatic environments suggest that Atribacteria are similarly heterotrophic (Webster et al., 2006a; Dodsworth et al., 2013; Rinke et al., 2013). The sediment Atribacteria bacterium SCGC AD-561-N23 SAG provides ample evidence for sugar and amino-sugar metabolism producing fermentation products such as acetate, ethanol, and $\mathrm{CO}_{2}$. Thus, Atribacteria are hypothesized to play a key role in regulating both the production of methane in marine sediment and the diversity of methane producers, depending on the abundance and type of fermentation products. Moreover, this study confirms that high latitude marine sediment from an organic-rich and highly productive continental margin environment displays similar microbial diversity patterns to lower latitude deep sediment, suggesting that attempts to constrain global sediment diversity (D'Hondt et al., 2004; Carr et al., 2013) can be expanded to include higher latitude sites with limited available data.

\section{References}

Altschul, S. F., Gish, W., Miller, W., Myers, E. W., and Lipman, D. J. (1990). Basic local alignment search tool. J. Mol. Biol. 215, 403-410. doi: 10.1016/S00222836(05)80360-2

Aziz, R., Bartels, D., Best, A., Dejongh, M., Disz, T., Edwards, R., et al. (2008). The RAST server: rapid annotations using subsystems technology. BMC Genomics 9:75. doi: 10.1186/1471-2164-9-75

Bankevich, A., Nurk, S., Antipov, D., Gurevich, A. A., Dvorkin, M., Kulikov, A. S., et al. (2012). SPAdes: a new genome assembly algorithm and its applications to single-cell sequencing. J. Comput. Biol. 19, 455-477. doi: $10.1089 / \mathrm{cmb} .2012 .0021$

Bowman, J. P., Rea, S. M., Mccammon, S. A., and Mcmeekin, T. A. (2000). Diversity and community structure within anoxic sediment from marine salinity meromictic lakes and a coastal meromictic marine basin, Vestfold Hills, Eastern Antarctica. Environ. Microbiol. 2, 227-237.

Caporaso, J. G., Kuczynski, J., Stombaugh, J., Bittinger, K., Bushman, F. D., Costello, E. K., et al. (2010). QIIME allows analysis of highthroughput community sequencing data. Nat. Methods 7, 335-336. doi: 10.1038/nmeth.f.303

Carr, S. A. (2012). Characterization of Microbial Communities and Carbon Flow Pathways within Antarctic Marine Sediments. Ph.D. thesis, Colorado School of Mines, Golden, CO.

Carr, S. A., Vogel, S. W., Dunbar, R. B., Brandes, J., Spear, J. R., Levy, R., et al. (2013). Bacterial abundance and composition in marine sediments beneath the Ross Ice Shelf, Antarctica. Geobiology 11, 377-395. doi: 10.1111/gbi. 12042

Chouari, R., Le Paslier, D., Daegelen, P., Ginestet, P., Weissenbach, J., and Sghir, A. (2005). Novel predominant archaeal and bacterial groups revealed by molecular analysis of an anaerobic sludge digester. Environ. Microbiol. 7, 1104-1115. doi: 10.1111/j.1462-2920.2005.00795.x

\section{Acknowledgments}

The authors thank the shipboard party of IODP Expedition 318 for supporting this work, especially co-chief scientists Carlota Escutia and Henk Brinkhuis, Staff Scientist Adam Klaus, and Rob Dunbar and the geochemistry team: James Bendle, Christina van de Flierdt, and Francisco J. JimenezEspejo. We thank Chuck Pepe-Ranney for assistance with bioinformatics, Ramunas Stepanauskas and Nicole Poulton of the Single Cell Genomics Center for supporting single cell sorting, and the Joint Genome Institute for genome amplification and annotation. Lastly, we are thankful for the comments of our reviewers. This research used samples and data provided by the Integrated Ocean Drilling Program (IODP). Funding for this work was provided in part by a fellowship to SC from the Center for Dark Energy Biosphere Investigations (C-DEBI) funded by the U.S. National Science Foundation (OCE-0939564). The work conducted by the U.S. Department of Energy Joint Genome Institute is supported by the Office of Science of the U.S. Department under contract No. DE-AC02-05CH11231. This is C-DEBI contribution number 275 .

\section{Supplementary Material}

The Supplementary Material for this article can be found online at: http://journal.frontiersin.org/article/10.3389/fmicb. 2015.00872

Clingenpeel, S. (2015). JGI Microbial Single Cell Program, Single Cell Data Decontamination. Available at: https://img.jgi.doe.gov/er/doc/ SingleCellDataDecontamination.pdf

Colwell, F. S., Boyd, S., Delwiche, M. E., Reed, D. W., Phelps, T. J., and Newby, D. T. (2008). Estimates of biogenic methane production rates in deep marine sediments at Hydrate Ridge, Cascadia Margin. Appl. Environ. Microbiol. 74, 3444-3452. doi: 10.1128/AEM.02114-07

Cottrell, M. T., and Kirchman, D. L. (2000). Natural assemblages of marine proteobacteria and members of the Cytophaga-Flavobacter cluster consuming low- and high-molecular-weight dissolved organic matter. Appl. Environ. Microbiol. 66, 1692-1697. doi: 10.1128/AEM.66.4.1692-169 7.2000

Desantis, T. Z., Hugenholtz, P., Larsen, N., Rojas, M., Brodie, E. L., and Keller, K. (2006). Greengenes, a chimera-checked 16S rRNA gene database and workbench compatible with ARB. Appl. Environ. Microbiol. 72, 5069-5072. doi: 10.1128/AEM.03006-05

D’Hondt, S., Jørgensen, B. B., Miller, D. J., Batzke, A., Blake, R., Cragg, B. A., et al. (2004). Distributions of microbial activities in deep subseafloor sediments. Science 306, 2216-2221. doi: 10.1126/science.1101155

D'Hondt, S., Rutherford, S., and Spivack, A. J. (2002). Metabolic activity of subsurface life in deep-sea sediments. Science 295, 2067-2070. doi: $10.1126 /$ science. 1064878

Dodsworth, J. A., Blainey, P. C., Murugapiran, S. K., Swingley, W. D., Ross, C. A., Tringe, S. G., et al. (2013). Single-cell and metagenomic analyses indicate a fermentative and saccharolytic lifestyle for members of the OP9 lineage. Nat. Commun. 4, 1854. doi: 10.1038/ncomms 2884

Don, R. H., Cox, P. T., Wainwright, B. J., Baker, K., and Mattick, J. S. (1991). Touchdown PCR to circumvent spurious priming during gene amplification. Nucleic Acids Res. 19, 4008. doi: 10.1093/nar/19.14.4008

Eddy, S. R. (2011). Accelerated profile HMM searches. PLoS Comput. Biol. 7:e1002195. doi: 10.1371/journal.pcbi.1002195 
Edgar, R. C. (2010). Search and clustering orders of magnitude faster than BLAST. Bioinformatics 26, 2460-2461. doi: 10.1093/bioinformatics/btq461

Escutia, C., Brinkhuis, H., and Klaus, A. (2008). Cenozoic East Antarctic ice sheet evolution from Wilkes Land margin sediments. IODP Sci. Prosp. 318, Figure AF1. doi: 10.2204/iodp.sp.318.2008

Expedition 318 Scientists. (2011a). "Site U1357," in Proc. IODP, 318, eds C. Escutia, H. Brinkhuis, A. Klaus, and the Expedition 318 Scientists (Tokyo: Integrated Ocean Drilling Program Management International, Inc.).

Expedition 318 Scientists. (2011b). "Methods," in Proc. IODP, 318, eds C. Escutia, H. Brinkhuis, A. Klaus, and the Expedition 318 Scientists (Tokyo: Integrated Ocean Drilling Program Management International, Inc.).

Gies, E. A., Konwar, K. M., Beatty, J. T., and Hallam, S. J. (2014). Illuminating microbial dark matter in meromictic Sakinaw Lake. Appl. Environ. Microbiol. 80, 6807-6818. doi: 10.1128/AEM.01774-14

Goris, J., Konstantinidis, K. T., Klappenbach, J. A., Coenye, T., Vandamme, P., and Tiedje, J. M. (2007). DNA-DNA hybridization values and their relationship to whole-genome sequence similarities. Int. J. Syst. Evol. Microbiol. 57, 81-91. doi: $10.1099 /$ ijs. $0.64483-0$

Hugenholtz, P., Pitulle, C., Hershberger, K. L., and Pace, N. R. (1998). Novel division level bacterial diversity in a Yellowstone Hot Spring. J. Bacteriol. 180, 366-376.

Inagaki, F., Nunoura, T., Nakagawa, S., Teske, A., Lever, M., Lauer, A., et al. (2006). Biogeographical distribution and diversity of microbes in methane hydrate-bearing deep marine sediments on the Pacific Ocean Margin. PNAS 103, 2815-2820. doi: 10.1073/pnas.0511033103

Inagaki, F., Suzuki, M., Takai, K., Oida, H., Sakamoto, T., Aoki, K., et al. (2003). Microbial communities associated with geological horizons in coastal subseafloor sediments from the Sea of Okhotsk. Appl. Environ. Microbiol. 69, 7224-7235. doi: 10.1128/AEM.69.12.7224-7235.2003

Jahnke, R. A. (1996). The global ocean flux of particulate organic carbon: a real distribution and magnitude. Global Biogeochem. Cycles 10, 71-88. doi: 10.1029/95GB03525

Jahnke, R., and Jackson, G. (1992). "The Spatial Distribution of Sea Floor Oxygen Consumption in the Atlantic and Pacific Oceans," in Deep-Sea Food Chains and the Global Carbon Cycle, eds G. Rowe and V. Pariente (Dordrecht: Springer).

Kallmeyer, J., Pockalny, R., Adhikari, R. R., Smith, D. C., and D'Hondt, S. (2012). Global distribution of microbial abundance and biomass in subseafloor sediment. PNAS 109, 16213-16216. doi: 10.1073/pnas.1203849109

Kaster, A.-K., Mayer-Blackwell, K., Pasarelli, B., and Spormann, A. M. (2014). Single cell genomic study of Dehalococcoidetes species from deep-sea sediments of the Peruvian Margin. ISME J. 8, 1831-1842. doi: 10.1038/ismej.2014.24

Kirchman, D. L., Hanson, T. E., Cottrell, M. T., and Hamdan, L. J. (2014). Metagenomic analysis of organic matter degradation in methane-rich Arctic Ocean sediments Limnol. Oceanography 59, 548-559.

Lane, D. J. (1991). "16S/23S rRNA sequencing," in Nucleic Acid techniques in Bacterial Systematics, eds E. Stackebrandt and M. Goodfellow (New York, NY: John Wiley \& Sons), 115-147.

Lasken, R. S. (2007). Single-cell genomic sequencing using Multiple Displacement Amplification. Curr. Opin. Microbiol. 10, 510-516. doi: 10.1016/j.mib.2007.08.005

Lasken, R. S., and McLean, J. S. (2014). Recent advances in genomic DNA sequencing of microbial species from single cells. Nat. Rev. Genet. 15, 577-584. doi: $10.1038 / \operatorname{nrg} 3785$

Lever, M. A., Alperin, M., Engelen, B., Inagaki, F., Nakagawa, S., Steinsbu, B. O., et al. (2006). Trends in basalt and sediment core contamination during IODP Expedition 301. Geomicrobiol. J. 23, 517-530. doi: 10.1080/0149045060 0897245

Lloyd, K. G., Schreiber, L., Petersen, D. G., Kjeldsen, K. U., Lever, M. A., Steen, A. D., et al. (2013). Predominant archaea in marine sediments degrade detrital proteins. Nature 496, 215-218. doi: 10.1038/nature12033

Markowitz, V. M., Chen, I.-M. A., Palaniappan, K., Chu, K., Szeto, E., Pillay, M., et al. (2014). IMG 4 version of the integrated microbial genomes comparative analysis system. Nucleic Acids Res. 42, D560-D567. doi: 10.1093/nar/ gkt963

Matsen, F. A., Kodner, R. B., and Armbrust, E. V. (2010). pplacer: linear time maximum-likelihood and Bayesian phylogenetic placement of sequences onto a fixed reference tree. BMC Bioinformatics 11:538. doi: 10.1186/1471-2105-11-538
McCarthy, A. J., and Williams, S. T. (1992). Actinomycetes as agents of biodegradation in the environment - a review. Gene 115, 189-192. doi: 10.1016/0378-1119(92)90558-7

Müller, B., Sun, L., and Schnürer, A. (2013). First insights into the syntrophic acetate-oxidizing bacteria - a genetic study. Microbiologyopen 2, 35-53. doi: $10.1002 / \mathrm{mbo} 3.50$

Nawrocki, E. P., Kolbe, D. L., and Eddy, S. R. (2009). Infernal 1.0: inference of RNA alignments. Bioinformatics 25, 1335-1337. doi: 10.1093/bioinformatics/ btp157

Newberry, C. J., Webster, G., Cragg, B. A., Parkes, R. J., Weightman, A. J., and Fry, J. C. (2004). Diversity of prokaryotes and methanogenesis in deep subsurface sediments from the Nankai Trough, Ocean Drilling Program Leg 190. Environ. Microbiol. 6, 274-287.

Niemann, H., Lösekann, T., De Beer, D., Elvert, M., Nadalig, T., Knittel, K., et al. (2006). Novel microbial communities of the Haakon Mosby mud volcano and their role as a methane sink. Nature 443, 854-858. doi: 10.1038/nature05227

Nobu, M. K., Narihiro, T., Rinke, C., Kamagata, Y., Tringe, S. G., Woyke, T., et al. (2015). Microbial dark matter ecogenomics reveals complex synergistic networks in a methanogenic bioreactor. ISME J. 9, 1710-1722. doi: 10.1038/ismej.2014.256

Osburn, M. R., Sessions, A. L., Pepe-Ranney, C., and Spear, J. R. (2011). Hydrogen-isotopic variability in fatty acids from Yellowstone National Park hot spring microbial communities. Geochim. Cosmochim. Acta 75, 4830-4845. doi: 10.1016/j.gca.2011.05.038

Overbeek, R., Olson, R., Pusch, G. D., Olsen, G. J., Davis, J. J., Disz, T., et al. (2013). The SEED and the Rapid Annotation of microbial genomes using Subsystems Technology (RAST). Nucleic Acids Res. 42, D206-D214.

Pruesse, E., Quast, C., Knittel, K., Fuchs, B. M., Ludwig, W., Peplies, J., et al. (2007). SILVA: a comprehensive online resource for quality checked and aligned ribosomal RNA sequence data compatible with ARB. Nucleic Acids Res. 35, 7188-7196. doi: 10.1093/nar/gkm864

Raghunathan, A., Ferguson, H. R., Bornarth, C. J., Song, W., Driscoll, M., and Lasken, R. S. (2005). Genomic DNA amplification from a single bacterium. Appl. Environ. Microbiol. 71, 3342-3347. doi: 10.1128/AEM.71.6.33423347.2005

Reed, D. W., Fujita, Y., Delwiche, M. E., Blackwelder, D. B., Sheridan, P. P., Uchida, T., et al. (2002). Microbial communities from methane hydrate-bearing deep marine sediments in a Forearc Basin. Appl. Environ. Microbiol. 68, 37593770. doi: 10.1128/AEM.68.8.3759-3770.2002

Richter, M., and Rosselló-Móra, R. (2009). Shifting the genomic gold standard for the prokaryotic species definition. PNAS 106, 19126-19131. doi: 10.1073/pnas.0906412106

Rinke, C., Schwientek, P., Sczyrba, A., Ivanova, N. N., Anderson, I. J., Cheng, J.-F., et al. (2013). Insights into the phylogeny and coding potential of microbial dark matter. Nature 499, 431-437. doi: 10.1038/nature12352

Rochelle, P. A., Fry, J. C., John Parkes, R., and Weightman, A. J. (1992). DNA extraction for $16 \mathrm{~S}$ rRNA gene analysis to determine genetic diversity in deep sediment communities. FEMS Microbiol. Lett. 100, 59-65. doi: 10.1111/j.15746968.1992.tb05682.x

Schrempf, H. (2001). Recognition and degradation of chitin by streptomycetes. Antonie Van Leeuwenhoek 79, 285-289. doi: 10.1023/A:10120582 05158

Stamatakis, A., Hoover, P., and Rougemont, J. (2008). A rapid bootstrap algorithm for the RAxML web servers. Syst. Biol. 57, 758-771. doi: $10.1080 / 10635150802429642$

Stemmer, W. P. C. (1991). A 20-minute ethidium bromide/high-salt extraction protocol for plasmid DNA. Biotechniques 130, 726.

Stepanauskas, R. (2012). Single cell genomics: an individual look at microbes. Curr. Opin. Microbiol. 15, 613-620. doi: 10.1016/j.mib.2012.09.001

Stepanauskas, R., and Sieracki, M. E. (2007). Matching phylogeny and metabolism in the uncultured marine bacteria, one cell at a time. PNAS 104, 9052-9057. doi: 10.1073/pnas.0700496104

Swan, B. K., Martinez-Garcia, M., Preston, C. M., Sczyrba, A., Woyke, T., Lamy, D., et al. (2011). Potential for chemolithoautotrophy among ubiquitous bacteria lineages in the dark ocean. Science 333, 1296-1300. doi: $10.1126 /$ science. 1203690

Teske, A., Hinrichs, K.-U., Edgcomb, V., De Vera Gomez, A., Kysela, D., Sylva, S. P., et al. (2002). Microbial diversity of hydrothermal sediments in the Guaymas 
Basin: evidence for anaerobic methanotrophic communities. Appl. Environ. Microbiol. 68, 1994-2007. doi: 10.1128/AEM.68.4.1994-2007.2002

Teske, A., and Sørensen, K. B. (2007). Uncultured archaea in deep marine subsurface sediments: have we caught them all? ISME J. 2, 3-18. doi: 10.1038/ismej.2007.90

Uyeda, K., and Rabinowitz, J. C. (1971). Pyruvate-Feerdoxin Oxidoreductase IV Studies on the reaction mechanism. J. Biol. Chem. 246, 3120-3125.

Vorob'ev, A., Manucharova, N., Yaroslavtsev, A., Belova, E., Zvyagintsev, D., and Sudnitsyn, I. (2007). The composition of the chitinolytic microbial complex and its effect on chitin decomposition at various humidity levels. Microbiology 76, 557-562. doi: 10.1134/S0026261707050074

Wasmund, K., Schreiber, L., Lloyd, K. G., Petersen, D. G., Schramm, A., Stepanauskas, R., et al. (2014). Genome sequencing of a single cell of the widely distributed marine subsurface Dehalococcoidia, phylum Chloroflexi. ISME J. 8, 383-397. doi: 10.1038/ismej.2013.143

Webster, G., Parkes, J. R., Cragg, B. A., Newberry, C. J., Weightman, A. J., and Fry, J. C. (2006a). Prokaryotic community composition and biogeochemical processes in deep subseafloor sediments from the Peru Margin. FEMS Microbiol. Ecol. 58, 65-85. doi: 10.1111/j.1574-6941.2006.00147.x

Webster, G., Watt, L. C., Rinna, J., Fry, J. C., Evershed, R. P., Parkes, R. J., et al. (2006b). A comparison of stable-isotope probing of DNA and phospholipid fatty acids to study prokaryotic functional diversity in sulfate-reducing marine sediment enrichment slurries. Environ. Microbiol. 8, 1575-1589. doi: 10.1111/j.1462-2920.2006.01048.x

Webster, G., Parkes, R. J., Fry, J. C., and Weightman, A. J. (2004). Widespread occurrence of a novel division of bacteria identified by $16 \mathrm{~S}$ rRNA gene sequences originally found in deep marine sediments. Appl. Environ. Microbiol. 70, 5708-5713. doi: 10.1128/AEM.70.9.5708-5713.2004

Webster, G., Yarram, L., Freese, E., Köster, J., Sass, H., Parkes, R. J., et al. (2007). Distribution of candidate division JS1 and other Bacteria in tidal sediments of the German Wadden Sea using targeted 16S rRNA gene PCR-DGGE. FEMS Microbiol. Ecol. 62, 78-89. doi: 10.1111/j.1574-6941.2007.00372.x

Wilms, R., Köpke, B., Sass, H., Chang, T. S., Cypionka, H., and Engelen, B. (2006). Deep biosphere-related bacteria within the subsurface of tidal flat sediments. Environ. Microbiol. 8, 709-719.

Yarza, P., Yilmaz, P., Pruesse, E., Glockner, F. O., Ludwig, W., Schleifer, K.-H., et al. (2014). Uniting the classification of cultured and uncultured bacteria and archaea using 16S rRNA gene sequences. Nat. Rev. Microbiol. 12, 635-645. doi: 10.1038/nrmicro3330

Zhou, J., Bruns, M. A., and Tiedje, J. M. (1996). DNA recovery from soils of diverse composition. Appl. Environ. Microbiol. 62, 316-322.

Conflict of Interest Statement: The authors declare that the research was conducted in the absence of any commercial or financial relationships that could be construed as a potential conflict of interest.

Copyright (c) 2015 Carr, Orcutt, Mandernack and Spear. This is an open-access article distributed under the terms of the Creative Commons Attribution License (CC BY).

The use, distribution or reproduction in other forums is permitted, provided the original author(s) or licensor are credited and that the original publication in this journal is cited, in accordance with accepted academic practice. No use, distribution or reproduction is permitted which does not comply with these terms. 